\title{
Synthesis and evaluation of novel bioactive composite starch/bioactive glass microparticles
}

\author{
G. A. Silva, ${ }^{1-3}$ F. J. Costa, ${ }^{1}$ O. P. Coutinho, ${ }^{1,4}$ S. $\operatorname{Radin}^{3}{ }^{3}$ P. Ducheyne ${ }^{3}$ R. L. Reis $^{1,2}$ \\ ${ }^{1} 3 B^{\prime}$ 's Research Group, University of Minho, Campus de Gualtar, 4710-057 Braga, Portugal \\ ${ }^{2}$ Department of Polymer Engineering, University of Minho, Campus de Azurém, 4800-058 Guimarães, Portugal \\ ${ }^{3}$ Center for Bioactive Materials and Tissue Engineering, University of Pennsylvania, Hayden Hall Suite 120, 3320 \\ Smith Walk, Philadelphia, Pennsylvania 19104-6315 \\ ${ }^{4}$ Department of Biology, University of Minho, Campus de Gualtar, 4710-057 Braga, Portugal
}

Received 15 December 2003; revised 6 April 2004; accepted 6 May 2004

Published online 11 June 2004 in Wiley InterScience (www.interscience.wiley.com). DOI: 10.1002/jbm.a.30099

\begin{abstract}
The aim of the development of composite materials is to combine the most desired properties of two or more materials. In this work, the biodegradable character, good controlled-release properties, and natural origin of starch-based biomaterials are combined with the bioactive and bone-bonding properties of bioactive glass (BG). Novel, bioactive composite starch-BG microparticles were synthesized starting from a blend of starch and polylactic acid (50\%/50\% wt) with BG 45 S5 powder using a simple emulsion method. Morphological and chemical characterization showed that these particles exhibited a spherical morphology with sizes up to $350 \mu \mathrm{m}$ and that BG $45 \mathrm{~S} 5$ was incorporated successfully into the composite particles. Upon immersion in a solution simulating body fluids, for periods up to 3 weeks, their bioactive nature was confirmed, as a calcium-phosphate layer resembling biological apatite was formed onto their surface. The short-term cytotoxicity of
\end{abstract}

these materials was also tested by placing 24-h leachables of the materials extracted in culture medium in contact with a fibroblastic cell line (L929) up to $72 \mathrm{~h}$. At this time period, two biochemical tests-MTT and total protein quantification-were performed. The results showed that these materials are not cytotoxic. These results constitute the basis of future encapsulation studies using bone-acting therapeutic agents such as bone morphogenetic proteins or other bonerelevant factors. The particles developed here may be very useful for applications in which controlled release, degradability, and bone-bonding ability are the main requirements. (C) 2004 Wiley Periodicals, Inc. J Biomed Mater Res 70A: 442-449, 2004

Key words: natural origin; biodegradable; starch; bioactive glass; bioactive; microparticles; composites; short-term cytotoxicity

\section{INTRODUCTION}

A bioactive bone-bonding material is one that elicits a specific biological response at the interface of the material, which results in the formation of a bond between the tissues and the material. ${ }^{1,2}$ To date, no polymer displayed by itself a bioactive behavior (unless pretreatments have been performed). One strategy to promote their bioactivity is to combine poly-

Correspondence to: G. A. Silva; e-mail: gsilva@dep. uminho.pt

Contract grant sponsor: Fundação Ciência e Tecnologia (FCT, Portugal); contract grant number: SFRH/BD/4648/ 2001

Contract grant sponsor: FCT Foundation for Science and Technology, through funds from the POCTI and/or FEDER programmes

Contract grant sponsor: National Institutes of Health; contract grant number: R01 DE

(C) 2004 Wiley Periodicals, Inc. mers and ceramics, thus creating composite materials that exhibit a range of properties that derive from both constituent materials. This way, it is possible to create materials that mitigate the lack of satisfactory properties of both polymers and ceramics. ${ }^{2}$ The use of starchbased materials can be justified by the well-known acidification phenomenon when using systems constituted by polylactic acid. Using natural-origin materials, this problem can be readily overcome because starch can be degraded within the body by several enzymes, ${ }^{3}$ resulting in degradation products (carbohydrates) that can be readily metabolized and excreted.

Starch-based polymers are being studied for a wide range of bone-related therapy applications, ranging from tissue engineering scaffolds, ${ }^{4}$ to bone cements ${ }^{5}$ and drug delivery systems. ${ }^{6}$ Its natural origin, together with its mechanical properties ${ }^{7-9}$ and biocompatibility $^{10,11}$ support the potential of starch-based materials in the biomedical field. As for bioactive glass 
(BG) $45 \mathrm{~S} 5$ (with a nominal composition of $46.1 \% \mathrm{SiO}_{2}$, $24.4 \% \mathrm{Na}_{2} \mathrm{O}, 26.9 \% \mathrm{CaO}, 2.6 \% \mathrm{P}_{2} \mathrm{O}_{5}$ mol \%), its rapid rate of surface reaction leads to fast tissue bonding when compared with other ceramic materials. Biological properties of BG 4555 have been extensively studied ${ }^{12-14}$ and, as shown in vitro, it was found to enhance extracellular matrix formation and promote the osteoblastic phenotypic expression. ${ }^{15}$

Starch microparticles have already been shown ${ }^{6}$ to be excellent for the controlled release of meclofenamic acid, an anti-inflammatory agent, and for the release of glucocorticoid agents such as dexamethasone. ${ }^{16}$ When combining these properties with the advantageous bone-bonding properties of BG $45 \mathrm{~S} 5$, there is a distinct potential for these particles to be used as controlled-release systems of either bone-acting drugs or growth factors. In principle, these systems would be able to bond to bone and at the same time act as drug-release systems. In theory, the presence of a bone-bonding material (BG) would enhance small-defect bone repair whereas, simultaneously, the biodegradable material would act as a scaffold for cell growth, by releasing incorporated growth factors. This release would stimulate cell proliferation and differentiation, thus achieving a faster repair.

In the present study, we synthesized composite microparticles composed of a starch-based material and of BG 45S5. These particles display a bioactive behavior, as seen by the formation of a calcium-phosphate layer resembling biological apatite at their surface upon immersion in a solution simulating body fluid. As for all newly proposed biomaterials, a cytotoxic screening must be performed as a preliminary step in the process of the determination of the compatibility with biological systems (biocompatibility). In this work, the short-term cytotoxicity of the developed materials was tested by means of minimum essential medium (MEM) extraction tests.

\section{MATERIALS AND METHODS}

\section{Materials}

A commercial blend of starch and polylactic acid (SPLA) (50\%/50\% wt) (Novamont, Italy) was used as raw material for the production of the microparticles. BG $45 \mathrm{~S} 5$ (46.1\% $\mathrm{SiO}_{2}, 24.4 \% \mathrm{Na}_{2} \mathrm{O}, 26.9 \% \mathrm{CaO}, 2.6 \% \mathrm{P}_{2} \mathrm{O}_{5}, \mathrm{~mol} \%$ ) was obtained from MO-SCI (Rolla, MO) and ground before use to a particle size smaller than $60 \mu \mathrm{m}$.

For particle synthesis, methylene chloride and polyvinyl alcohol $87-89 \%$ hydrolyzed, were used as received. The following chemicals were used for preparing the simulated body solution, herein designated as TE (Tris with electrolytes): $0.05 \mathrm{M}$ Tris buffer solution, Trizma- $\mathrm{HCl}$, sodium chloride $(\mathrm{NaCl})$, potassium chloride $(\mathrm{KCl})$, sodium hydrogen carbonate $\left(\mathrm{NaHCO}_{3}\right)$, magnesium chloride hexahydrated
$\left(\mathrm{MgCl}_{2} \cdot 6 \mathrm{H}_{2} \mathrm{O}\right)$, magnesium sulphate heptahydrated $\left(\mathrm{MgSO}_{4} \cdot 7 \mathrm{H}_{2} \mathrm{O}\right)$, dipotassium hydrogen phosphate anhydrous $\left(\mathrm{K}_{2} \mathrm{HPO}_{4}\right)$, and calcium chloride anhydrous $\left(\mathrm{CaCl}_{2}\right)$, used as received.

\section{Synthesis of SPLA and SPLA/BG particles}

SPLA particles were produced by an emulsification method adapted from Qiu et al. ${ }^{17}$ The method was modified as follows: $1 \mathrm{~g}$ of SPLA was dissolved in $10 \mathrm{~mL}$ of methylene chloride and this solution was added to $200 \mathrm{~mL}$ of a stirring $0.5 \%$ polyvinyl alcohol solution and emulsified for $5 \mathrm{~h}$ in a Caframo dual-range stirrer (Fisher Scientific, Hampton, NH) at a speed of $660 \mathrm{rpm} / \mathrm{min}$. The particles were then washed and separated from the solution by filtration. They were dried, separated by size, and stored in a desiccator.

The SPLA/BG composite particles were produced following the methodology described above, to which $30 \%$ of the starch-based material weight of BG $45 \mathrm{~S} 5$ was added to the starch solution.

\section{SPLA and SPLA/BG particles morphological characterization}

The synthesized particles were morphologically characterized by light microscopy and scanning electron microscopy (SEM) and size distribution was determined for each condition by sieving. The particles were observed and photographed in an optical microscope with an image acquisition system (high-resolution color video camera and ImagePro Plus analysis software; Media Cybernetics, Silver Spring, MD). SEM analysis was performed on gold-coated samples.

Size distribution was obtained by determining the weight of each of the obtained fractions after sieving in a sonic sifter (ATM sonic sifter, model L3P; ATM Co., Milwaukee, WI). For the determination of the size distribution, measurements were made at least in triplicate.

\section{Immersion-bioactivity evaluation}

SPLA and SPLA/BG particles of a size range between 210-350 $\mu \mathrm{m}$ were used for in vitro testing of their bioactivity in a $0.05 M$ Tris hydroxymethyl aminomethane-buffered solution complemented with electrolytes typical for plasma (TE). The use of this solution was described previously. ${ }^{18}$ SPLA-based particles were immersed in TE at a ratio of 5 and $3 \mathrm{mg} / \mathrm{mL}$, for SPLA and SPLA/BG particles, respectively, in a $\mathrm{CO}_{2}$ incubator at $37^{\circ} \mathrm{C}$. The vials were placed on an orbital shaker at a rotational speed of $150 \mathrm{rpm}$ for up to 21 days without solution exchange. At designated time points $(1,2,3,7,10,14$, and 21 days), the samples were removed from the shaker, the $\mathrm{pH}$ was measured, and the particles were separated from the solution by filtration. The latter were then dried and stored in a desiccator until further analysis. The post-immersion solutions were used to per- 
form chemical analysis, namely for changes in $\mathrm{Ca}, \mathrm{Si}$, and $\mathrm{P}$ concentrations. $\mathrm{Ca}$ and $\mathrm{Si}$ concentrations were measured by atomic absorption spectrophotometry. For the Ca measurements, a solution of $1 \% \mathrm{LaCl} 3$ was used, whereas the $\mathrm{Si}$ measurements were performed directly from the post-immersion solution. For the P measurements, an ultravioletvisible spectrophotometer was used at $400 \mathrm{~nm}$ and a colorimetric method was employed. ${ }^{19}$ Samples were also analyzed by ICP-OES (inductively coupled plasma-optical emission spectroscopy).

Further characterization of the immersed particles was performed using Fourier transform infrared-attenuated reflection (FTIR-ATR), SEM/energy dispersive X-ray spectroscopy (EDS) analysis and X-ray diffraction (XRD) analysis.

\section{Short-term cytotoxicity evaluation}

For cytotoxicity evaluation by indirect contact with the materials, two different tests were performed, namely MTT and total protein quantification test.

The cells used in this study were an immortalized cell line of subcutaneous areolar fibroblasts from mouse origin purchased from Collection of Cell Culture (ECACC, UK, ref. 85011425), designated L929. The cells were grown in monolayer systems in Dulbecco's modified eagle medium supplemented (as described in the next section) and used between passages 6 and 12 .

\section{MTT}

The MTT test is a biochemical test widely used to assess cytotoxicity by measuring cell viability and proliferation in a qualitative way. ${ }^{20,21}$ This biochemical test is based in the reduction of [3-(4,5-dimethylthiazol-2-yl)-2,4-diphenyltetrazolium bromide] (which is water-soluble and has a yellow tonality) by the cell mitochondrial enzyme succinate dehydrogenase, yielding a purple-color salt insoluble in water. ${ }^{22}$ The salt absorbs at a wavelength of $570 \mathrm{~nm}$ and because only living cells have the capability to metabolize the MTT, it gives a measurement of the viable cells. ${ }^{22}$

The procedure followed for this test was as described previously ${ }^{23}$ and corresponds to the ISO MEM elution test for short-term cytotoxicity assessment. Briefly, SPLA and SPLA/BG particles were placed in conic tubes with Dulbecco's modified Eagle medium and placed under constant shaking $(60 \mathrm{rpm})$ at $37^{\circ} \mathrm{C}$ for $24 \mathrm{~h}$ for the materials to release eventual leachables (formation of extracts from the materials). An extraction control was performed, which consists of Dulbecco's modified Eagle medium, placed in the same conditions as the samples. This control was performed to assure that the extraction conditions by themselves do not alter the properties of the culture medium. After $24 \mathrm{~h}$, the extracts were filtered through a $0.45-\mu \mathrm{m}$ pore size filter, placed in contact with an $80-90 \%$ confluence cells' monolayer and further incubated for $72 \mathrm{~h}$. After this time period, the viability of the cells was evaluated by the MTT test by measuring the optical density. All the materials were tested in 10 replicates for each extract for at least two independent

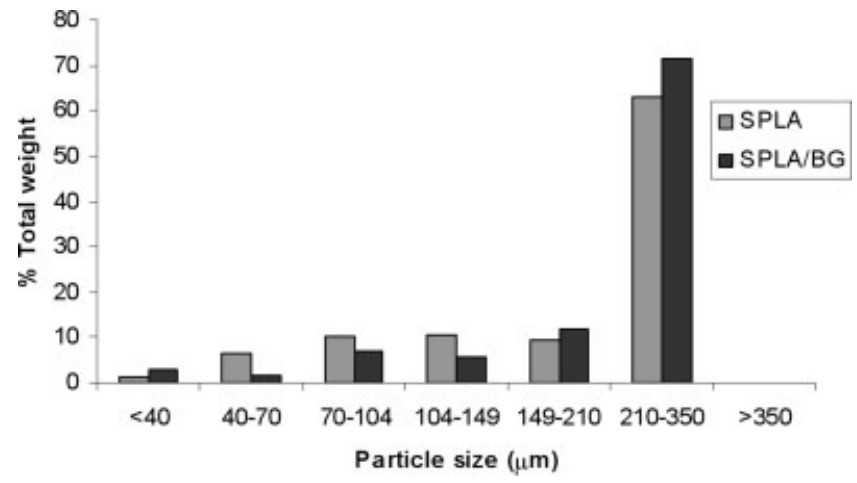

Figure 1. SPLA and SPLA/BG particle size distribution. After sieving, each size interval was weighted and its relative amount was determined. The graph shows that both conditions present similar size-distribution patterns, which indicates that the addition of BG 45S5 powder does not seem to affect the size distribution of the particles.

experiments with reproducible results. The results are expressed as a percentage of the control (scored as $100 \%$ viability) as mean \pm standard errors.

\section{Total protein quantification}

The method that was used to quantify the total protein uses the Micro BCA Protein Assay Reagent Kit, in which bicinchoninic acid (BCA) is the detection reagent for a $\mathrm{Cu}$ complex, which is formed when $\mathrm{Cu}^{2+}$ is reduced by proteins in an alkaline environment. ${ }^{24}$ The purple-color product is due to the chelation of two molecules of BCA with one $\mathrm{Cu}$ ion. This complex is water-soluble and absorbs at $562 \mathrm{~nm}$, and its optical density is linearly correlated with protein concentration. ${ }^{24}$

The procedure followed is as described for the MTT test. After the 72-h incubation, the cells were washed with phosphate-buffered saline and the BCA reagent was added. After an incubation period, the optical densities were measured. Total protein (in micrograms) was determined using a bovine serum albumin standard curve.

All the materials were tested in 10 replicates for each extract for at least three separate experiments, with reproducible results. The results are expressed as percentage of the control (scored as $100 \%$ viability) as mean \pm standard errors.

\section{RESULTS AND DISCUSSION}

\section{Synthesis of SPLA and SPLA/BG particles}

The size distribution for SPLA and SPLA/BG particles (Fig. 1) clearly shows that the size range of 210-350 $\mu \mathrm{m}$ predominates, whereas particles with sizes $>350 \mu \mathrm{m}$ are absent and $<40 \mu \mathrm{m}$ are only a minor fraction. This allows stating that the addition of BG to form composite particles does not significantly 

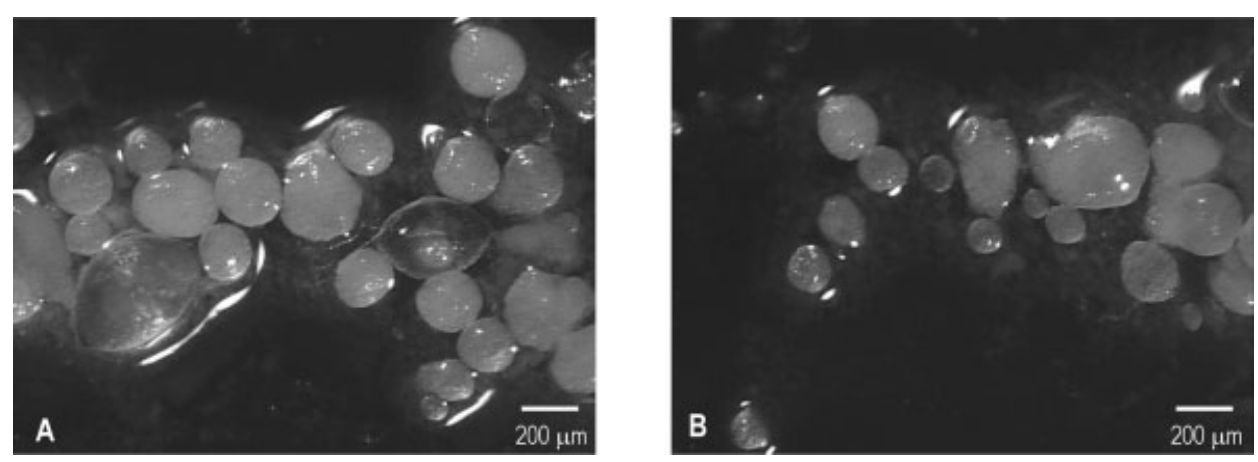

Figure 2. Light optical microscopy images of SPLA (A) and SPLA/BG (B) particles. No morphological differences between polymeric and composite particles are visible.

affect the size distribution of the starch-based particles.

\section{Morphology of SPLA and SPLA/BG particles}

The morphology of polymer and composite particles was evaluated by optical microscopy (Fig. 2) coupled to an image acquisition system. It was also analyzed using SEM (Fig. 3).

The morphology of the particles as revealed by light microscopy was indifferent of the type of particles. The particles were approximately spherical, which was further confirmed by SEM analysis. In addition, this examination also showed that their surfaces were quite similar, with smooth areas intercalating with rougher ones, and with some cavities being present. In Figure 3(C) (a detail of a typical particle surface), some pores/cavities can be seen. On the composite particles there are no surface features that might be distinctive for the presence of BG $45 \mathrm{~S} 5$.

\section{Bioactivity evaluation: chemical analysis}

To evaluate the bioactivity of the synthesized particles, both sets of samples-SPLA and SPLA/BG particles-were immersed in a Tris buffer complemented with electrolytes (TE) for durations up to 21 days. Figure $4(\mathrm{~A}-\mathrm{C})$ displays the results of the chemical
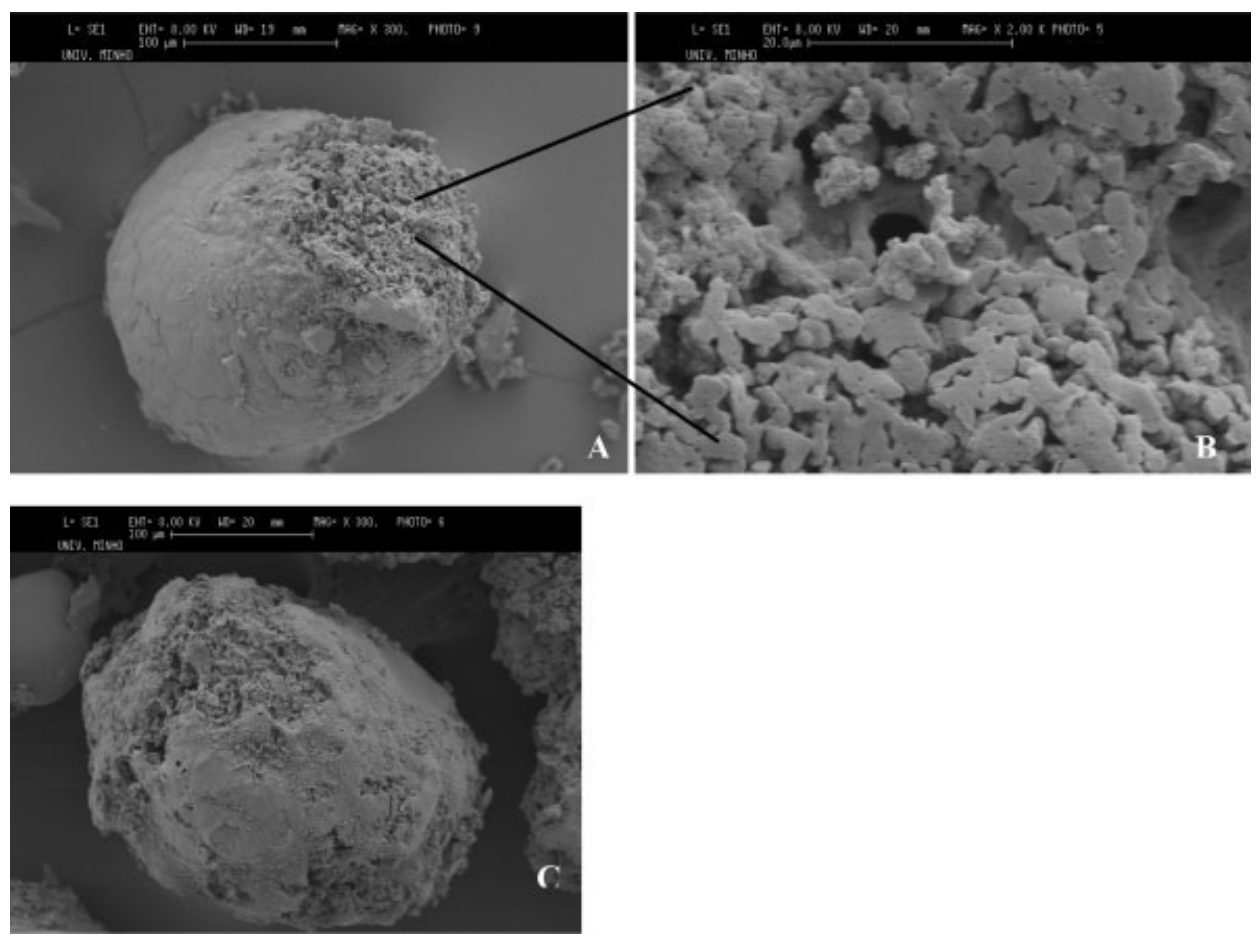

Figure 3. SEM image of SPLA (A; B, a detail of the rougher surface) and SPLA/BG particles (C). There are no clear morphological differences between the two types of particles. 


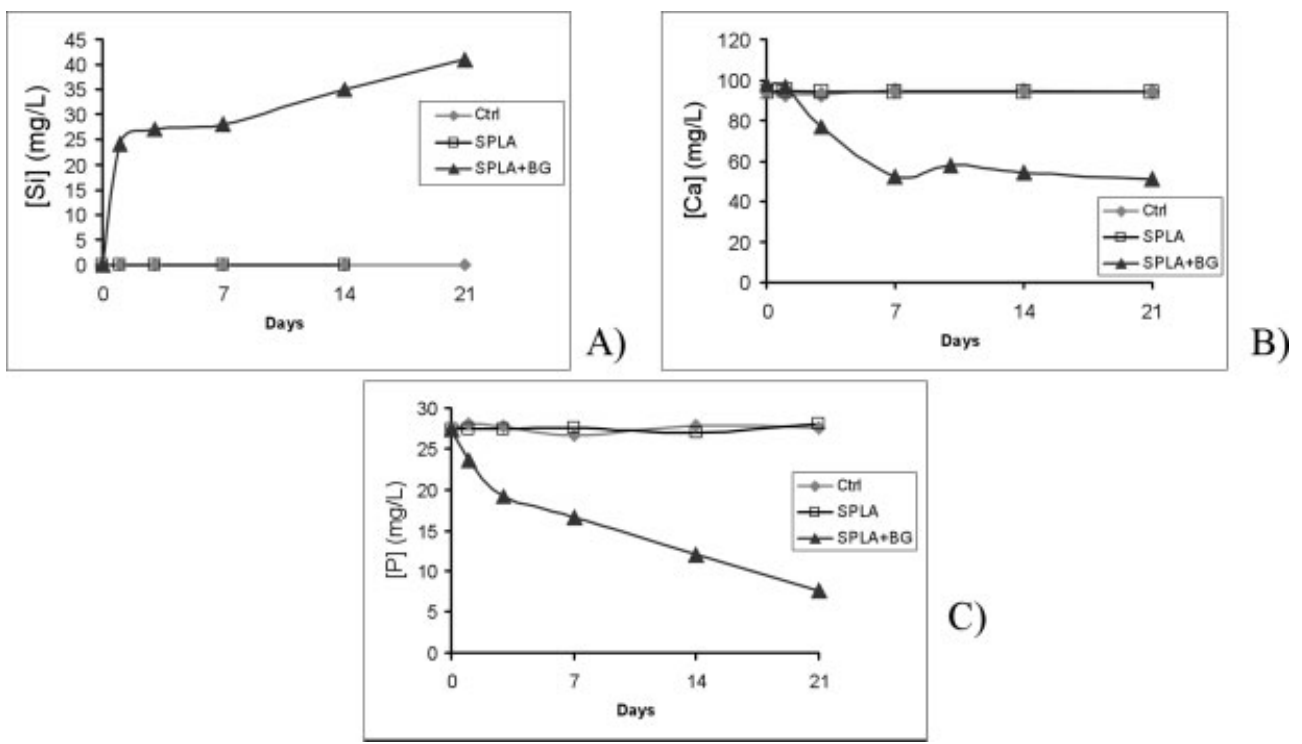

Figure 4. Si release (A) and $\mathrm{Ca}(\mathrm{B})$ and $\mathrm{P}(\mathrm{C})$ uptake profiles during 21 days of immersion in TE (control). Measurements were made on control solutions (Ctrl) and solutions in which either SPLA or SPLA/BG particles were previously immersed.

analysis of $\mathrm{Si}, \mathrm{Ca}$, and $\mathrm{P}$ in immersion solution for the analyzed time points.

As can be seen in Figure 4(A), BG $45 \mathrm{~S} 5$ was successfully incorporated into SPLA/BG particles, as seen by the cumulative $\mathrm{Si}$ release for the immersion times. As for SPLA particles, no Si release was observed, as would be expected. Together with the Si elution from SPLA/BG particles, variations in Ca and P concentrations were also observed. Regarding calcium, its concentration in solution decreased, indicating that this ion was being deposited at the surface of the particles [Fig. 4(B)]. Interestingly, this behavior was only observed with the composite particles. Concomitantly, there was also a decrease in phosphate concentration on the solution [Fig. 4(C)], as described for calcium. For all the immersion periods, SPLA particles did not produce an uptake of these ions, suggesting absence of bioactive behavior of these microparticles.

\section{Morphological analysis of immersed SPLA/BG particles}

SEM micrographs of the surface of SPLA and SPLA/BG particles immersed for 21 days are shown in Figure 5. Evident are the differences between the surface of SPLA (A) and SPLA/BG (B,C) particles, where SPLA does not evidence Ca-P precipitation oppositely to SPLA/BG particles, which have their surface fully covered by Ca-P nuclei. The morphological analysis of the surface of SPLA/BG particles, combined with the EDS analysis (Fig. 6), confirms the presence of a layer of calcium phosphate [Fig. 5(B)]. Higher-magnification Figure $5(\mathrm{C})$ shows that this layer displays the typical morphology of a bone-like calcium phosphate.

EDS analysis (Fig. 6) was performed to establish the ionic composition of the layer, which is confirmed to be a calcium phosphate by the respective peaks. The presence of chloride is the result of the synthesis in which methylene chloride is used. There is some residual chloride after washing of the particles.

The immersed particles were also evaluated by FTIRATR (Fig. 7) and although there is some overlap between the spectra of the polymer and the typical spectra of BG $45 \mathrm{S5}$, it is possible to observe the typical P-O band of reacted BG 45S5 at $1080 \mathrm{~cm}^{-1}$ at 21 days. Other characteristic BG $45 S 5$ bands are not visible because of the overlap with some of the polymer bands.

Finally, the XRD pattern (Fig. 8) of the particles was obtained, and upon comparison with the reference hydroxylapatite (HA) spectra, the appearance of the characteristic peaks of HA on the composite particles is visible after day 14 of immersion.

In Figure 8, the XRD patterns of the composite particles are shown after 0,14 , and 21 days of immersion in TE. The arrows indicate the main peaks characteristic of HA. It is seen that at 21 days the main HA peaks as well as some less evident peaks (indicated by the dashed arrows) are present in the composite microparticles. This indicates that at the surface of the composite particles a Ca-P layer similar to HA was formed.

\section{Short-term cytotoxicity}

The results for the short-term cytotoxicity evaluation are present in Figures 9 (MTT) and 10 (total protein quantification). 

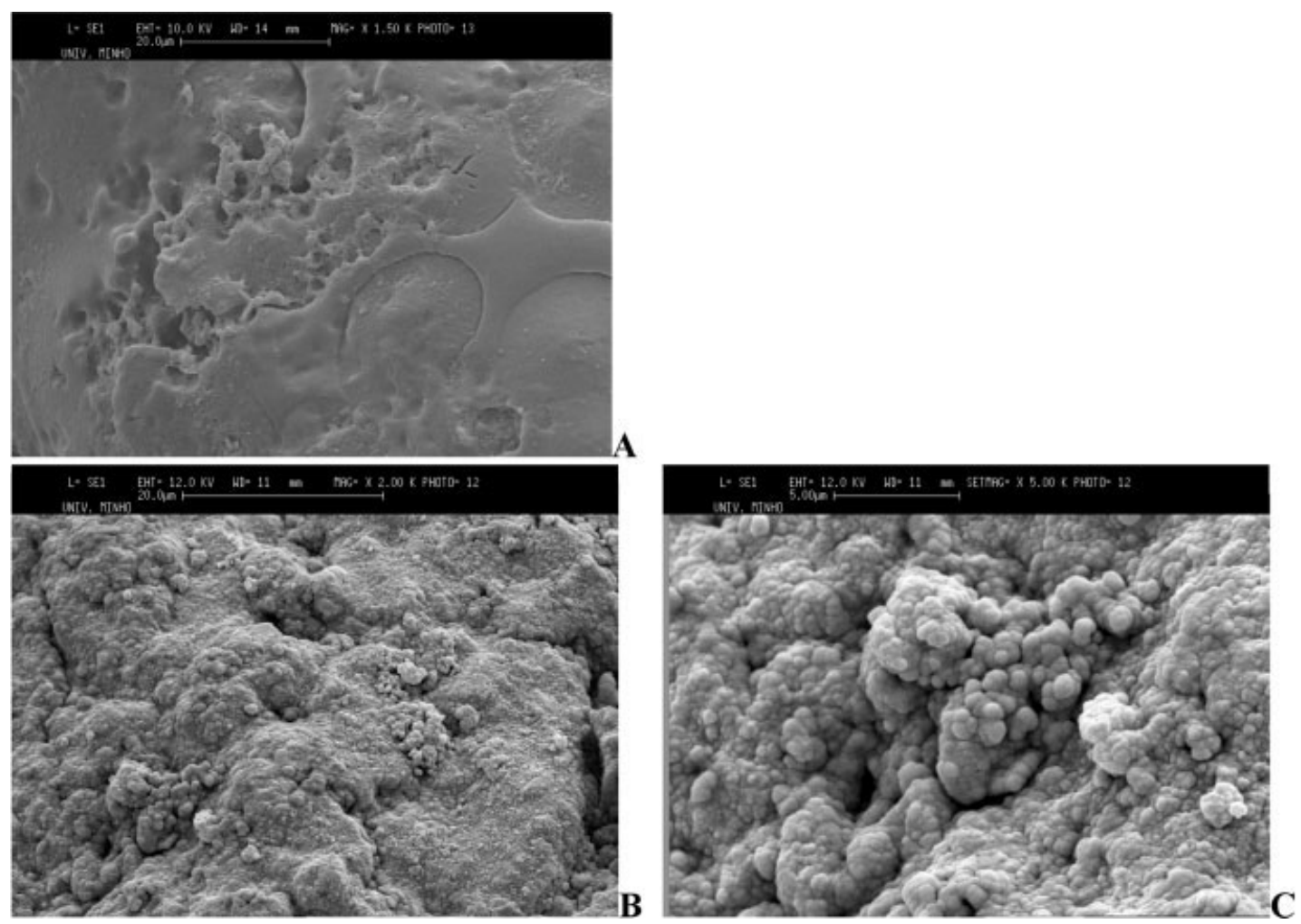

Figure 5. SEM images with increasing magnification of the surface of SPLA (A) and SPLA/BG microparticles immersed for 21 days. The surface of SPLA particles does not evidence any Ca-P deposition (A), whereas for SPLA/BG particles, the surface is fully covered with a Ca-P layer (B) having the globular structure (C).

As for total protein quantification, the results are presented as percentages of the control, meaning that the values obtained are in comparison with the $100 \%$ proliferation attributed to the control.

As can be seen, both materials-SPLA and SPLA/ $\mathrm{BG}$ - present values close to the one from the control, for both materials above $89 \%$, which is a good indication of their noncytotoxic behavior.

This result is well correlated with the MTT results, in which both materials present again viability percentages above $86 \%$ (Fig. 10). Some difference is observed between the results for the polymer and com-

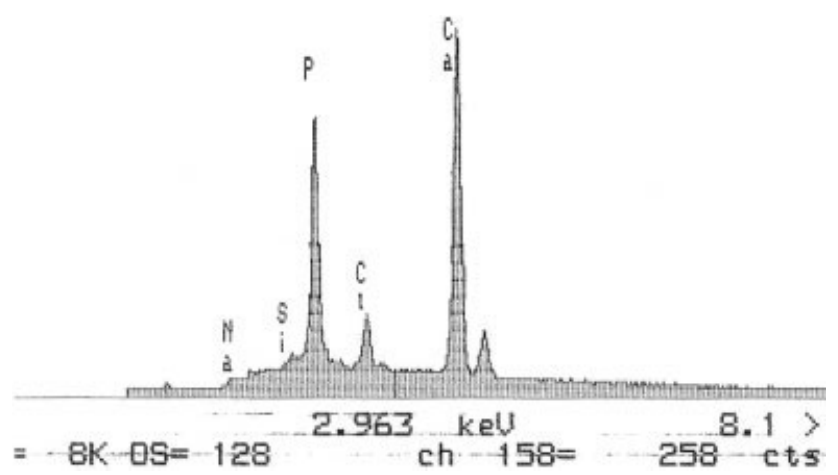

Figure 6. EDS of SPLA/BG particles immersed for 21 days. Calcium and phosphate peaks confirm the presence of a calcium-phosphate layer at the surface.
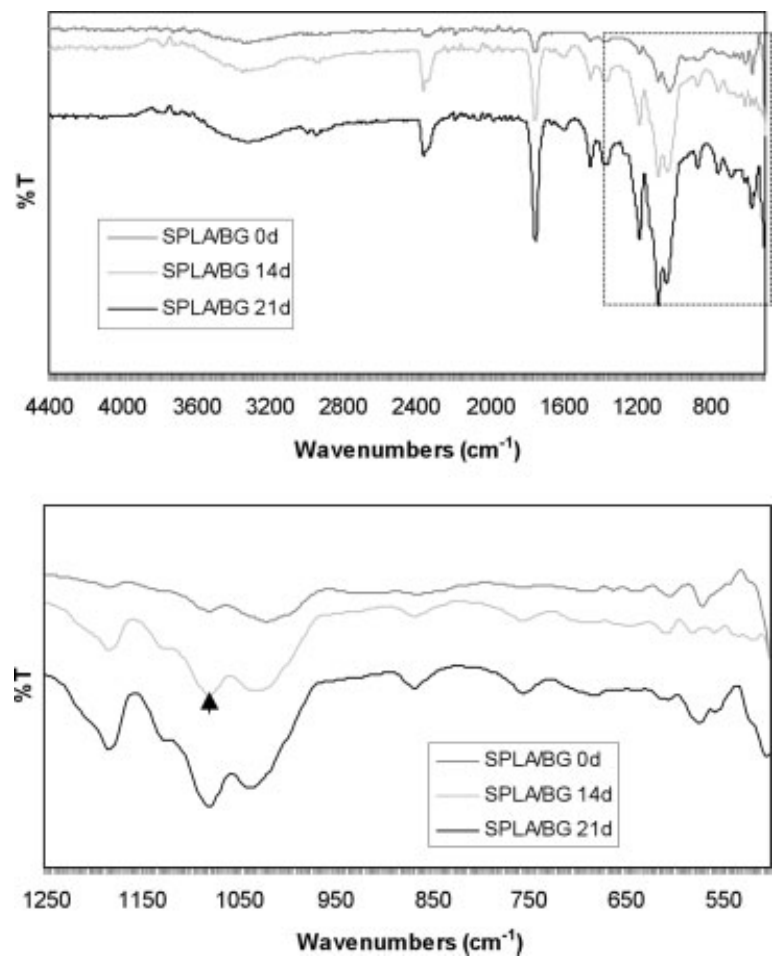

Figure 7. FTIR spectra for SPLA/BG particles at 0, 14, and 21 days of immersion, (A) full spectra and (B) spectra from $1300-500 \mathrm{~cm}^{-1}$. The arrow indicates the characteristic P-O band that appears when a Ca-P layer is formed on the surface of the material. 


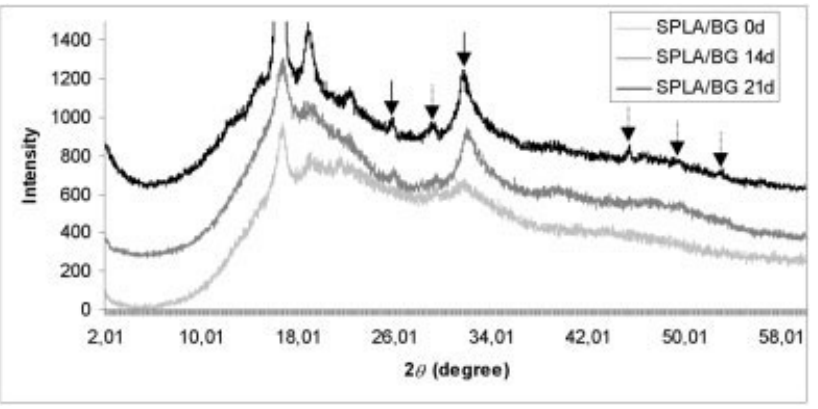

Figure 8. XRD pattern of SPLA/BG particles immersed for 0,14 , and 21 days in TE. The full arrows indicate the main peaks of HA, and dashed arrows indicate secondary peaks as seen at 21 days of immersion. The reference pattern of HA is 3-747.

posite materials and the $\mathrm{T}$ test was performed to assess whether significant differences existed between the tested materials for each of the tests, but there were no significant differences between the two materials $(p>0.05)$.

\section{CONCLUSIONS}

The synthesis of both polymeric and composite starch/BG particles was successfully achieved, as particles with spherical morphology and a well-defined size range were produced. Immersion in a simulated body fluid for periods up to 21 days showed that BG $45 \mathrm{~S} 5$ was incorporated into the polymer particles (as seen by Si release from composite particles) and that its presence rendered the particles bioactive. The bioactive nature of the composite starch-BG 45S5 particles was identified through morphological, chemical,

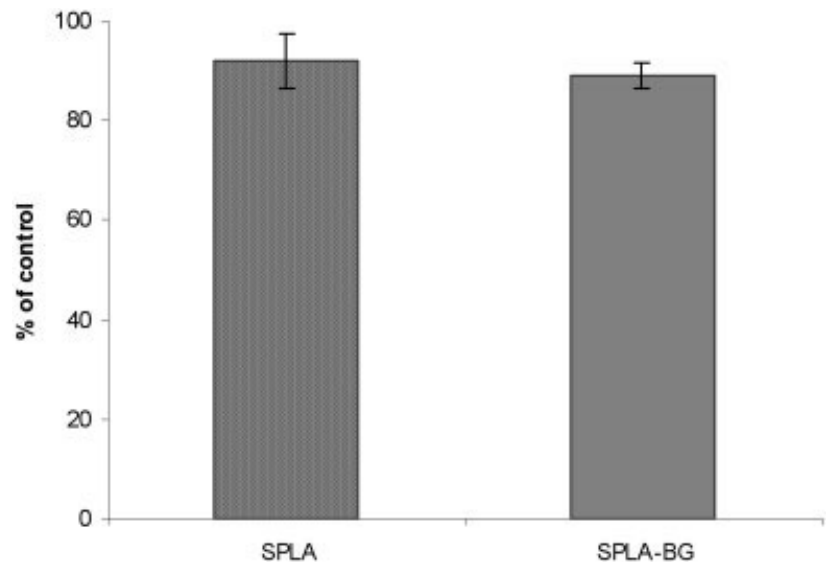

Figure 9. Total protein quantification for SPLA and SPLA/BG particles. The values shown are presented as a percentage of the control (cells cultured with culture medium, scored $100 \%$ ) and for both materials the values are $>88 \%$. No statistically significant differences are observed between both materials $(p>0.05)$.

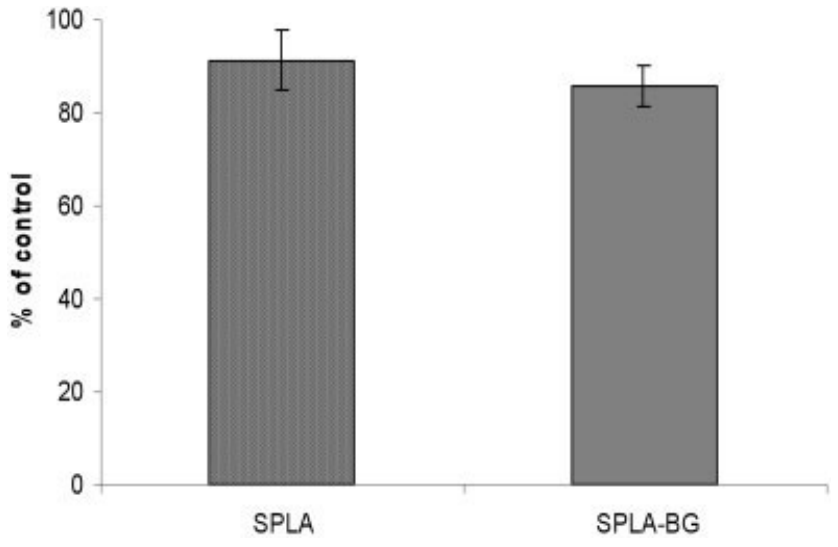

Figure 10. MTT test for SPLA and SPLA/BG particles. The values for both materials are presented as a function of the control (cells cultured with culture medium, scored 100\%). Both materials present values $>86 \%$. No statistically significant differences are observed between both materials $(p>$ $0.05)$.

and structural analyses. These experiments revealed the presence of a calcium phosphate layer at the surface of SPLA/BG particles.

As for their short-term cytotoxicity, these materials have shown a noncytotoxic behavior when evaluated in indirect contact tests with a cell line. Both performed tests-MTT and total protein quantificationhave shown to yield identical results, and the tested materials have shown a viability profile close to the one from control cells.

The aim is to use these particles as systems for the release of bone growth factors, such as bone morphogenetic proteins (BMPs). By virtue of a combination of bioactive behavior herein assessed and by the ability to encapsulate bioactive agents, ${ }^{16}$ these microparticles have a great potential for a controlled growth factor release related to bone applications.

Other properties that will also be studied are their bone bonding ability in vivo and their use as injectable bone fillers. Future studies will include the loading of the particles with BMPs to study the incorporation and release of BMP into the particles, in vitro cell culture studies, and in vivo studies in small animals.

G. A. Silva is a recipient of a grant from Fundação Ciência e Tecnologia (FCT, Portugal). The help of William Romanov and António Azevedo for the XRD analysis is gratefully acknowledged.

\section{References}

1. Hench L, Andersson O. Bioactive glasses. In: Hench L, Wilson $\mathrm{J}$, editors. An introduction to bioceramics. Advanced series in bioceramics I. Singapore: World Scientific; 1993. p 41-62.

2. Ducheyne P. Bioceramics: material characteristics versus in vivo behavior. J Biomed Mater Res 1987;21(A2):219-236. 
3. Gomes ME, Ribeiro AS, Malafaya PB, Reis RL, Cunha AM. A new approach based on injection moulding to produce biodegradable starch based polymeric scaffolds. Biomaterials 2001; 22:883-889.

4. Reis RL, Cunha AM. Starch and starch based thermoplastics. Biological and biomimetic materials. In: Jurgen Buschow $\mathrm{KH}$, Cahn RW, Flemings MC, Ilschner B, Kramer EJ, Mahajan S, editors. Encyclopedia of materials science and technology. Vol. 11. Amsterdam: Pergamon-Elsevier Science; 2001. p 8810-8816.

5. Boesel LF, Mano JF, Elvira C, San Román J, Reis RL. Hydrogels and hydrophilic partially degradable bone cements based on biodegradable blends incorporating starch. In: Chiellini E, editor. Biodegradable polymers and plastics. Dordrecht: Kluwer Academic; 2003. Forthcoming.

6. Malafaya PB, Elvira C, Gallardo A, San Román J, Reis RL. Porous starch-based drug delivery systems processed by a microwave treatment. J Biomater Sci Polym Ed 2001;12(11): 1227-1241.

7. Gomes ME, Godinho JS, Tchalamov D, Cunha AM, Reis RL. Alternative tissue engineering scaffolds based on starch: processing methodologies, morphology, degradation, mechanical properties and biological response. Mater Sci Eng C 2002;20(12):19-26.

8. Reis RL, Cunha AM, Allan PS, Bevis MJ. Mechanical behaviour of injection moulded starch based polymers. J Polym Adv Tech 1996;7:784-790.

9. Sousa RA, Mano JF, Reis RL, Cunha AM, Bevis MJ. Mechanical performance of starch based bioactive composite biomaterials molded with preferred orientation for potential medical applications. Polym Eng Sci 2002;42(5):1032-1045.

10. Marques AP, Reis RL, Hunt JA. In vitro evaluation of the biocompatibility of novel starch based polymeric and composite material. Biomaterials 2001;21:1471-1478.

11. Mendes SC, Bovell YP, Reis RL, Cunha AM, de Bruijn JD, van Blitterswijk CA. Biocompatibility testing of novel starch-based materials with potential application in orthopaedic surgery. Biomaterials 2001;22:2057-2064.
12. El-Ghannam A, Ducheyne P, Shapiro IM. Formation of surface reaction products on bioactive glass and their effects on the expression of the osteoblastic phenotype and the deposition of mineralized extracellular matrix. Biomaterials 1997;18:295-303.

13. Lai W, Garino J, Ducheyne P. Silicon excretion from bioactive glass implanted in rabbit bone. Biomaterials 2002;23:213-217.

14. Scheppers E, De Clercq M, Ducheyne P, Kempeneers R. Bioactive glass particulate material as a filler for bone lesions. Oral Rehab 1991;18:439-452.

15. Ducheyne P. Stimulation of biological function with bioactive glass. Mater Res Bull 1998;23:43-49.

16. Silva GA, Dias ACP, Coutinho OP, Reis RL. Entrapment ability and release profile of corticosteroids using starch-based microparticles. 2004. In preparation.

17. Qiu QQ, Ducheyne P, Ayyaswamy PS. New bioactive, degradable composite microspheres as tissue engineering substrates. J Biomed Mater Res 2000;52:66-76.

18. Abe Y, Kokubo T, Yamamuro T. Solutions able to reproduce in vivo surface-structure changes in bioactive glass-ceramic A-W. J Mater Sci Mater Med 1990;1:233.

19. Yee HY. A simplified method for automated phosphorus analysis of serum and urine. Clin Chem 1968;14:898-902.

20. Zeltinger J, Sherwood JK, Graham DA, Mueller R, Griffith LG. Effect of pore size and void fraction on cellular adhesion, proliferation and matrix deposition. Tissue Eng 2001;7(5):557572.

21. Slater TF, Sawyer B, Strauli U. Studies on succinate-tetrazolium reductase systems. III. Points of coupling of four different tetrazolium salts. Biochim Biophys Acta 1963;77:383-393.

22. Mosmann T. Rapid colorimetric assay for cellular growth and survival: application to proliferation and cytotoxicity assays. J Immunol Methods 1983;65:55-63.

23. Silva GA, Vaz CM, Coutinho OP, Cunha AM, Reis RL. In vitro degradation and cytocompatibility evaluation of novel soy and sodium caseinate-based membrane biomaterials. J Mater Sci Mater Med 2003;14:1055-1066.

24. Smith PK. Measurement of protein using bicinchoninic acid. Anal Biochem 1985;150:76-85. 